\title{
Rock magnetic properties of the late Pleistocene Loess-Paleosol deposits in Haro River area, Attock basin, Pakistan: Is magnetic susceptibility a proxy measure of paleoclimate?
}

\author{
Huma Akram, Mitsuo Yoshida, and Mirza Naseer Ahmad \\ Geoscience Laboratory, Geological Survey of Pakistan, Shahzad Town, P.O. Box 1461, Islamabad, Pakistan
}

(Received March 31, 1997; Revised December 15, 1997; Accepted December 17, 1997)

\begin{abstract}
Variations of rock-magnetic properties in a late Pleistocene (approx. 18-130 ka) Loess-Paleosol sequence of Haro River area, Attock basin, Pakistan were studied. Isothermal remanent magnetization (IRM) acquisition and thermomagnetic analyses of the samples indicate that magnetite and maghemite are the major magnetic minerals in these samples. Saturation isothermal remanent magnetization (SIRM), anhysteretic remanent magnetization (ARM), and the ratio ARM/SIRM disclose relative enrichment of ultra-fine magnetite/maghemite grains in the paleosols as compared to loess deposits, which suggests that the magnetite/maghemite is of pedogenic origin. Despite this enrichment, the low-field magnetic susceptibility is not always enhanced in paleosols in this sequence. In the Chinese Loess it has been believed that the observed lows and highs of magnetic susceptibility values respectively correspond to loess and paleosol sequences which indicates paleoclimatic change during the formation of the sequences. However, our observations in Pakistan's Loess-Paleosol sequence demonstrate that, although the ultrafine grained magnetite/maghemite may be produced by the process of pedogenesis, the low-field magnetic susceptibility record does not directly correlate with the alternation of loess and paleosol, and therefore the magnetic susceptibility can not simply be interpreted as a proxy for paleoclimate in the area.
\end{abstract}

\section{Introduction}

Magnetic properties of loess deposits carry high-resolution information of both geomagnetic and climatic histories. Certain loess sections have recorded the polarity history of the geomagnetic field and now provide essentially continuous magnetostratigraphic archives covering the last 2 3 Ma. Heller and Liu (1982) first established a detailed polarity stratigraphy for the Chinese Loess Plateau, after which a number of researchers worked on the Chinese Loess deposits in order to determine their age and to correlate them (Heller and Evans, 1995). These paleomagnetic studies mainly concern the natural remanent magnetization of the deposits, while another approach of magnetic study of loess deposits is also known. It is magnetic susceptibility study, or more generally rock-magnetic study, of loess deposits for paleoenvironmental applications. Many loess sections contain "fossil soils" (paleosols) which generally seem to be a trace of warmer and wetter climatic conditions corresponding to interglacial periods in contrast to the cold-arid environments during glacial periods in which the loess accumulated (Heller et al., 1991). It has been considered that the fine-grained materials comprising loess deposits were formed originally by glacial grinding, fluvio-glacial abrasion, or weathering in deserts. The very comprehensive and detailed study of Liu et al. (1985) verified that highs and lows of the susceptibility curves are closely correlated with

Copy right (C) The Society of Geomagnetism and Earth, Planetary and Space Sciences (SGEPSS); The Seismological Society of Japan; The Volcanological Society of Japan; The Geodetic Society of Japan; The Japanese Society for Planetary Sciences. the occurrence of paleosols and loess layers, respectively (Heller and Liu, 1984; Heller et al., 1991). The materials were transported by strong and turbulent winds over large areas. The wind transportation might have repeated frequently due to which erosion and redeposition of the materials took place. On the other hand paleosols were formed under a relatively humid and warm climate which would provoke intense weathering and soil formation at the surface of loess deposits. Less-weathered loess sequences, therefore, represent an arid and probably cool (=glacial/peri-glacial) climate during their accumulation, while the paleosols correspond to a more humid and warmer (=interglacial) climate.

A number of researchers have reported that the alternation of loess-paleosol sequences in the Chinese Loess Plateau strongly corresponds to the observed lows and highs of magnetic susceptibility (Heller and Liu, 1984; Heller et al., 1991; Hus and Han, 1992; Liu et al., 1993; Heller and Evans, 1995; Zheng et al., 1995). Similar phenomena were also observed in the Central Asian loess and paleosol sequence (Forster and Heller, 1994). The magnetic susceptibility contrast between loess and paleosols is such that the susceptibility value of paleosols is generally twice that of loess. The susceptibility variations have been correlated with the oxygen isotope record obtained from the deep sea sediments (Kukla et al., 1988; Maher and Thompson, 1992; Liu et al., 1994; Heller and Evans, 1995; Zheng et al., 1995), thus allowing a world-wide comparison of oceanic and continental Quaternary climate cycles. Magnetic susceptibility of loesspaleosol sequences is thus expected to provide authentic information about paleoenvironments. 


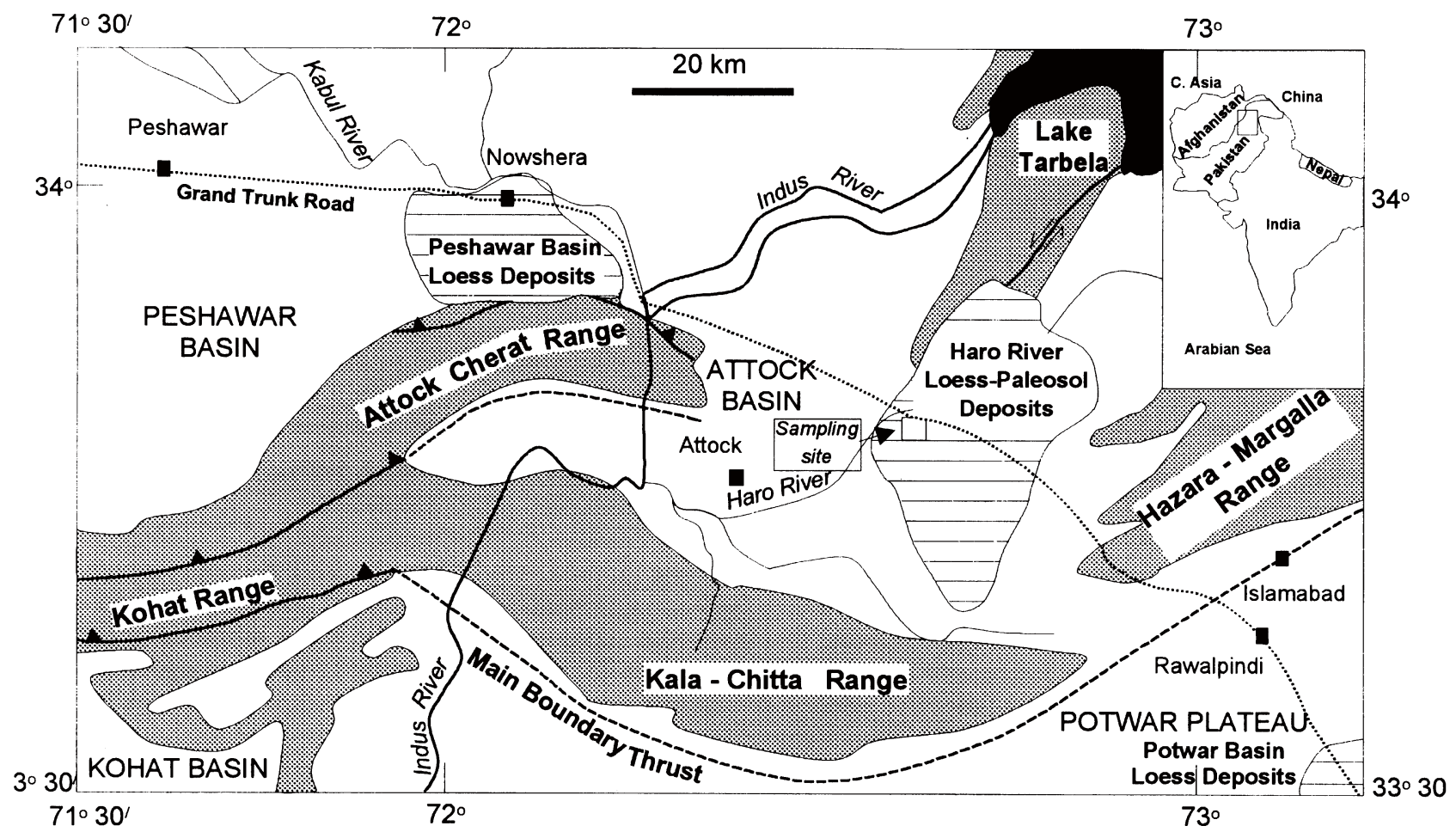

Fig. 1. Distribution of Late Pleistocene Loess-Paleosol deposits in the northern part of Pakistan and the location of the Loess-Paleosol section, Haro River Area, Attock Basin, Pakistan.

The cause of the variation of magnetic susceptibility in loess-paleosol sequence is, nevertheless, still equivocal. Much debate has been carried out about the cause, and basically two models are currently in the mainstream. One model suggests that the susceptibility enhancement of paleosols is due to the in situ pedogenesis during wetter and warmer times (Maher and Taylor, 1988; Zheng et al., 1991; Heller et al., 1993; Verosub et al., 1993; Evans and Heller, 1994). The argument is that the processes leading to the formation of soil during relatively warm and humid climates enhance the magnetic susceptibility compared with that of less-weathered pristine loess which accumulated during cold and arid intervals. The other model explains the decrease of magnetic susceptibility at loess horizons by the effect of dilution of constantly supplied magnetite particles with weakly magnetic materials (Kukla et al., 1988).

However, recent studies of other areas are reporting that not all loess-paleosol sequences show the same correlation between magnetic susceptibility and loess/paleosol facies change (Verosub et al., 1993; Oches and Banerjee, 1996; Chlachula et al., 1997). Here we provide the first rockmagnetic study of the loess-paleosol sequence in the Attock Basin, Pakistan, which gives discordant results with the "Chinese type" magnetic susceptibility change. We compare it with studies of other areas and discuss the rock magnetic properties of loess-paleosol deposits.

\section{Loess-Paleosol Section in Attock Basin}

The loess-paleosol section studied is located on the west bank of the Haro River (Latitude 33 $48^{\prime} 56^{\prime \prime} \mathrm{N}$, Longitude $72^{\circ} 32^{\prime} 24^{\prime \prime} \mathrm{E}$ ), south of the Islamabad-Peshawar Grand Trunk
Road, Attock district, Pakistan (Fig. 1). The dominant lithologies of the loess-paleosol deposits in the area are silt and clay with subordinate calcareous concretions. The base of the section is not exposed while the top of the section is covered with surface soil and grass. The paleosols are brownish gray in color with badland-forming vertical joints. The section measured is ca. $18.5 \mathrm{~m}$ thick and includes at least seven paleosol layers, PS-1, 2, 3, 4, 5, 6, and 7 in descending order (Fig. 2). These seven paleosols can also be classified into three paleosol zones based on stratigraphic position; the upper paleosol zone (PS-1-3), the middle paleosol zone (PS-4), and the lower paleosol zone (PS-5-7). The particlesize distribution and chemical composition can be distinguished clearly between loess and paleosol. These detailed lithologic and sedimentological descriptions are given in two companion papers (Zafar et al., 1996; Nizam-Din and Yoshida, 1997).

No direct geochronological data are available in the present section, however some thermoluminescence (TL) ages of the Peshawar and Potwar Loess deposits in adjacent areas have been reported 18,000 130,000 yr. BP (Rendell, 1988, 1989) which can be correlated with the Haro River LoessPaleosol deposits. Nizam-Din and Yoshida (1997) estimated that the Haro River Loess-Paleosol sequence ranges from the Last Interglacial to the Last Glacial Epoch and they correlate the Last Interglacial/Last Glacial boundary with the PS-4 paleosol horizon. These data suggest that the age of the Haro River Loess-Paleosol deposits is late Pleistocene.

The samples for rock-magnetic measurements were collected from 37 horizons in the sequence (Fig. 2). 


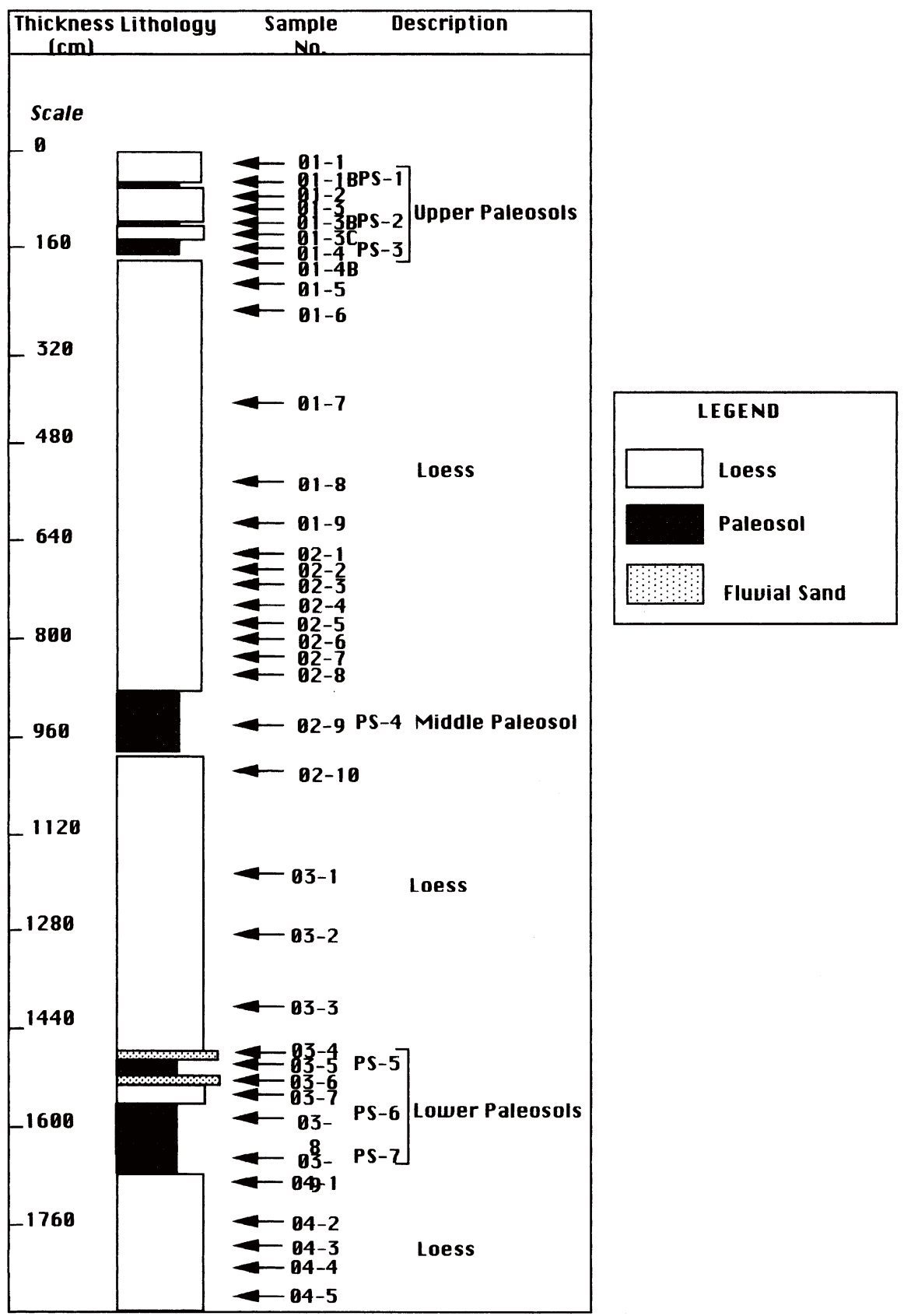

Fig. 2. Columnar section and sampling horizons of the Loess-Paleosol sequence, Haro River Area, Attock Basin, Pakistan.

\section{Magnetic Mineralogy}

\subsection{XRD and microscopic observation}

On the basis of X-ray diffraction (XRD) analyses (Siddiqui, 1996) and microscopic observation of bulk samples, the Haro River Loess-Paleosol deposits mainly consist of the following minerals: quartz $\left(\mathrm{SiO}_{2}\right)$, calcite $\left(\mathrm{CaCO}_{3}\right)$, albite $\left(\mathrm{NaAlSi}_{3} \mathrm{O}_{8}\right)$, vermiculite $\left(\mathrm{Mg}_{3}(\mathrm{AlSi})_{4} \mathrm{O}_{10}(\mathrm{OH})_{2} \cdot 4 \mathrm{H}_{2} \mathrm{O}\right)$, dickite $\left(\mathrm{Al}_{4} \mathrm{Si}_{4} \mathrm{O}_{10}(\mathrm{OH})_{8}\right)$, gypsum $\left(\mathrm{CaSO}_{4}\right)$, halite $(\mathrm{NaCl})$, and hornblende $\left(\mathrm{Ca}, \mathrm{Na}_{2}(\mathrm{Mg}, \mathrm{Fe}, \mathrm{Al})_{5}(\mathrm{AlSi})_{8} \mathrm{O}_{22}(\mathrm{OH})_{2}\right)$, which are paramagnetic and diamagnetic minerals. Due to low concentration $(<10 \%)$ in the samples, ferromagnetic minerals could not be detected by the above methods. Thus, to determine the ferromagnetic minerals in the loess-paleosol deposits, thermomagnetic analyses was performed.

\subsection{Thermomagnetic analyses}

The thermomagnetic analyses of the magnetically separated samples from all the sites were carried out by using a horizontally-balanced magnetic balance of an EIKO EB-4 system. The samples were crushed and the magnetic particles were separated with the help of a permanent magnet. The analyses were made under vacuum conditions $\left(\sim 10^{-3}\right.$ $\mathrm{mm} \mathrm{Hg}$ ) by applying a steady magnetic field of 250-300 mT at different temperatures ranging from room temperature to $750^{\circ} \mathrm{C}$. Different Curie temperatures were determined at sudden drops in strong field magnetization $\left(J_{S}\right)$ values in the heating/cooling $J_{S}$ - $T$ curves. Typical $J_{S}$ - $T$ curves for the loess and paleosol materials are shown in Fig. 3.

A Curie temperature of about $580^{\circ}-585^{\circ} \mathrm{C}$ can be observed 

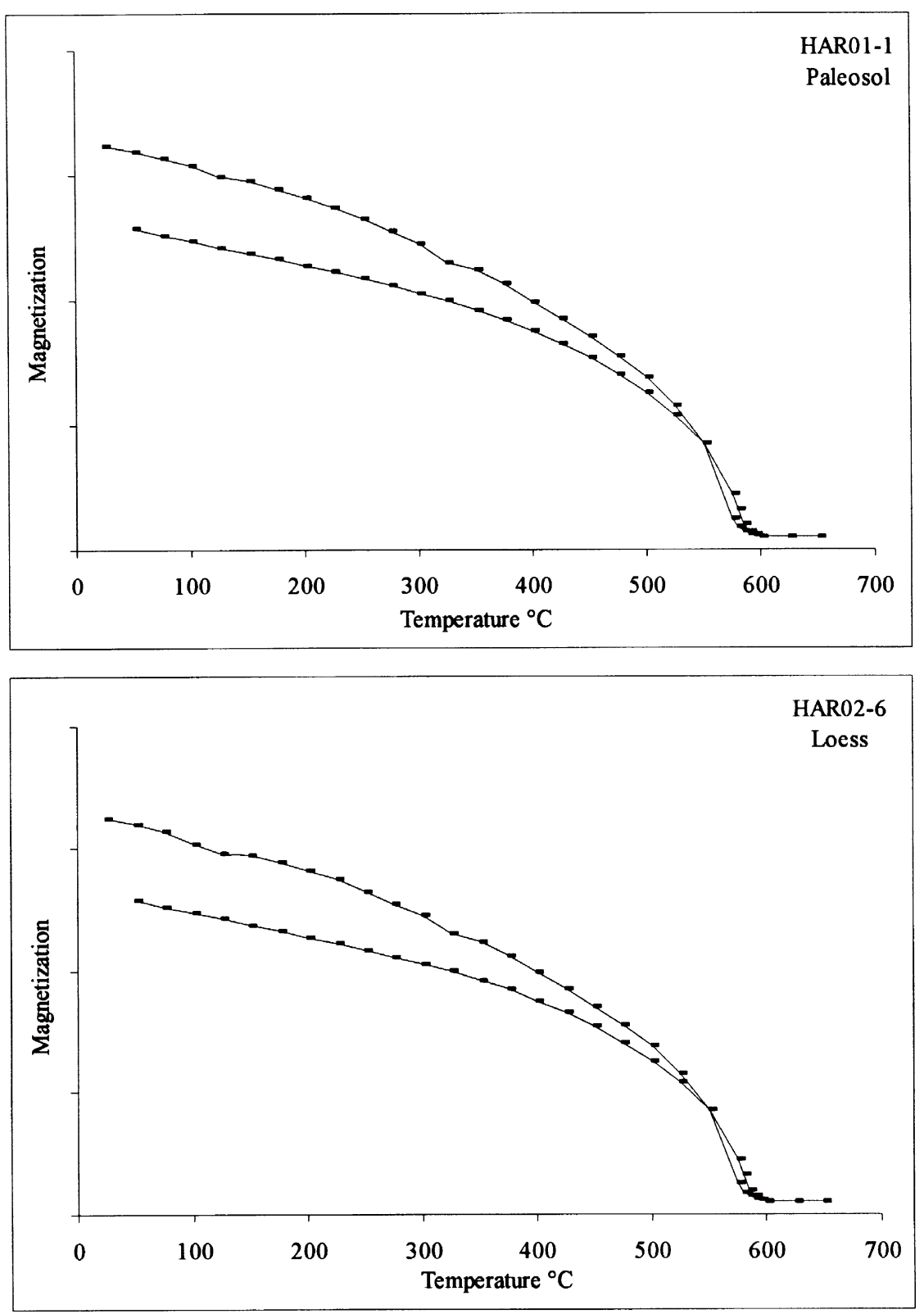

Fig. 3. Typical thermomagnetic curves of ferromagnetic minerals separated from loess (HAR02-6) and paleosol (HAR01-1B) units clearly showing the Curie temperature of magnetite. Other decreases of high-field magnetization $\left(J_{S}\right)$ can also be observed in the cooling curves.

in all the samples, while in some samples a Curie temperature of about $120^{\circ} \mathrm{C}$ is also detected. The heating and cooling curves in all the samples exhibit an irreversible pattern, showing a decrease in $J_{s}$ after heating, which suggests a transformation of high intensity magnetic minerals into a more weakly magnetized form. Similarly in some cases a small change of curvature in heating $J S-T$ curve is recognized around $330^{\circ} \mathrm{C}$, which demonstrates a magnetic phase transition during heating. The mineral maghemite is thermally unstable and converts to hematite as the heating progresses, leading to a decrease of magnetization on subsequent cooling. Beyond $600^{\circ} \mathrm{C}$ the signal is very weak compared to the sensitivity of the instrument. Hence it was not possible to discern any convincing signal from hematite, either newly created or originally present.

Similarly in all cases, a Curie temperature of $580^{\circ}-585^{\circ} \mathrm{C}$ corresponds to pure magnetite $\left(\mathrm{Fe}_{3} \mathrm{O}_{4}\right)$, and a small drop at about $120^{\circ} \mathrm{C}$ indicates the presence of goethite $(\alpha-\mathrm{FeOOH})$. The magnetic phase transition at around $330^{\circ} \mathrm{C}$ in heating is most probably caused by the conversion of maghemite $(\gamma-$ $\left.\mathrm{Fe}_{2} \mathrm{O}_{3}\right)$ into hematite $\left(\alpha-\mathrm{Fe}_{2} \mathrm{O}_{3}\right)$. The irreversible behavior of the $J_{S}-T$ curves (the decrease of $J_{s}$ at the room temperature after the heating), can be explained by the thermal decay of maghemite and the production of hematite. This type of irreversible $J s-T$ curve caused by maghemite is also common in the loess-paleosol sequence of China (Zheng et al., 1995).

\section{Rock Magnetic Measurements 4.1 IRM acquisition experiment}

To confirm the presence of the above mentioned ferromagnetic minerals, isothermal remanent magnetization (IRM) acquisition experiments were carried out using a TOKIN 0.7 T electromagnet, a pulse magnetizer MMPM-9, 

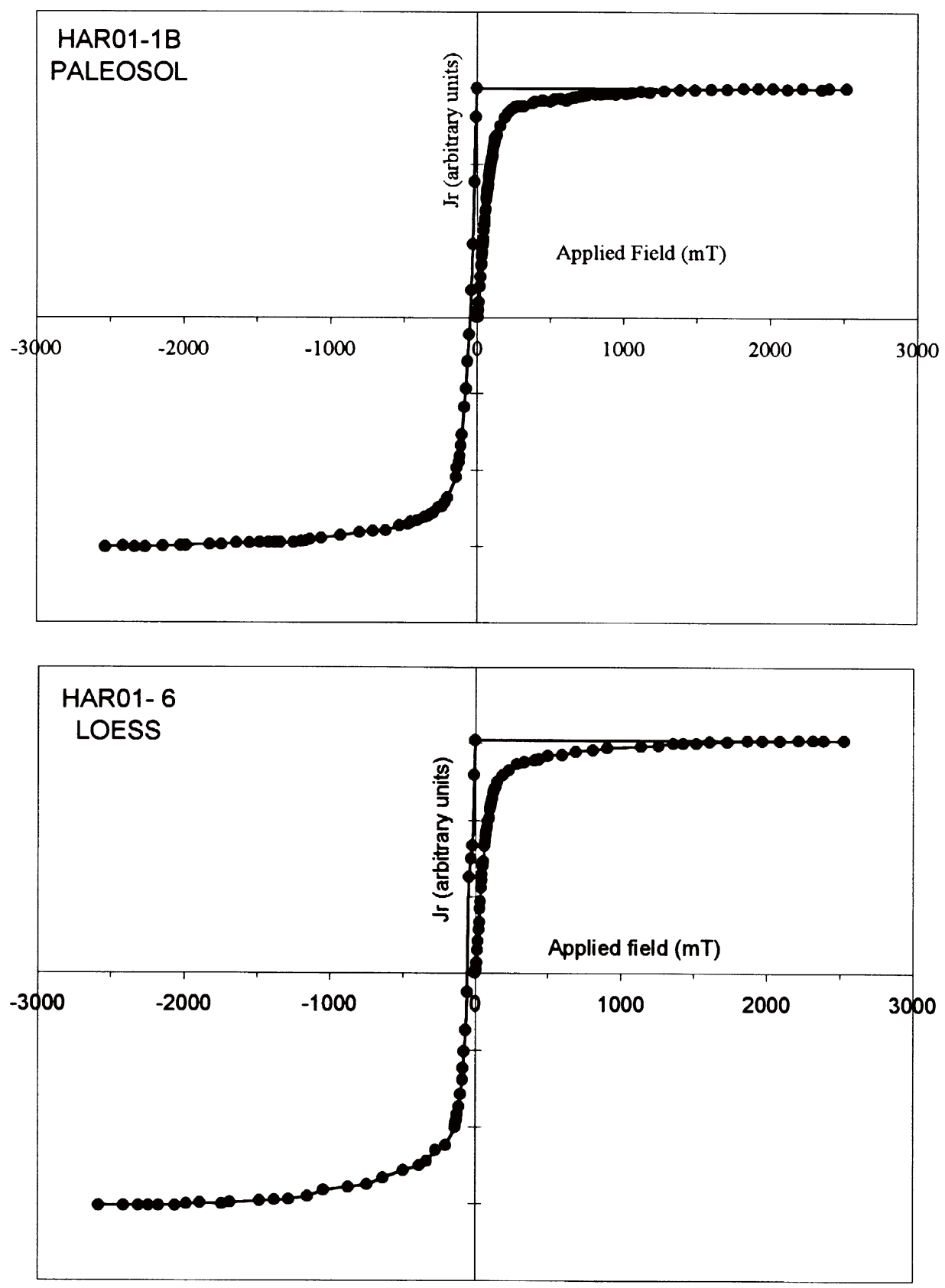

Fig. 4. Typical SIRM and back-IRM acquisition curves for samples from Loess-Paleosol units.

and a spinner magnetometer Natsuhara SSM-88. Samples were exposed to the magnetic field, which was progressively increased up to $2.5 \mathrm{~T}$. The IRM acquired under the $2.5 \mathrm{~T}$ field was considered to be the saturation IRM (SIRM). The back-field IRM, applying the field anti-parallel in direction to SIRM, was also progressively measured (Fig. 4). All the IRM acquisition curves reveal a drastic increase up to ca. $300 \mathrm{mT}$, after which the curves become more or less flattened but the point of complete saturation could not be achieved below 1.5 2.0 T. The sudden rise below $300 \mathrm{mT}$ in all of the IRM acquisition curves indicates the presence of low coercivity minerals, like magnetite and/or maghemite. The unsaturated component $(>300 \mathrm{mT})$ is carried by a high coercivity mineral, possibly goethite.

The degree of under-saturation of IRM above $300 \mathrm{mT}$ is expressed by a parameter representing degree of saturation computed from the IRM intensities at $300 \mathrm{mT}\left(\mathrm{IRM}_{0.3 \mathrm{~T}}\right)$ and $1.0 \mathrm{~T}\left(\mathrm{IRM}_{1.0 \mathrm{~T}}\right)$ field as follows:

$S(1.0 \mathrm{~T}-0.3 \mathrm{~T})=\left[1-\left\{\left(\mathrm{IRM}_{1.0 \mathrm{~T}}-\mathrm{IRM}_{0.3 \mathrm{~T}}\right) / \mathrm{IRM}_{1.0 \mathrm{~T}}\right\}\right] \times 100 \%$.

The values range from $67 \%$ to $99 \%$, and nearly all paleosols in the sequence show relatively high values except for PS6 , as compared to the loess deposits within this sequence (Fig. 5). It may reveal relative enrichment of low coercivity magnetite/maghemite in paleosol units.

\subsection{SIRM}

SIRM is a concentration-dependent parameter, i.e. it is high if the amount of ferromagnetic material present is high and vice versa. The intensity of SIRM of these LoessPaleosol deposits is in the range of 1.0 to $12.0 \mathrm{~A} / \mathrm{m}$. The SIRM of paleosol samples ( 1 to $7.5 \mathrm{~A} / \mathrm{m}$ ), near the base- 

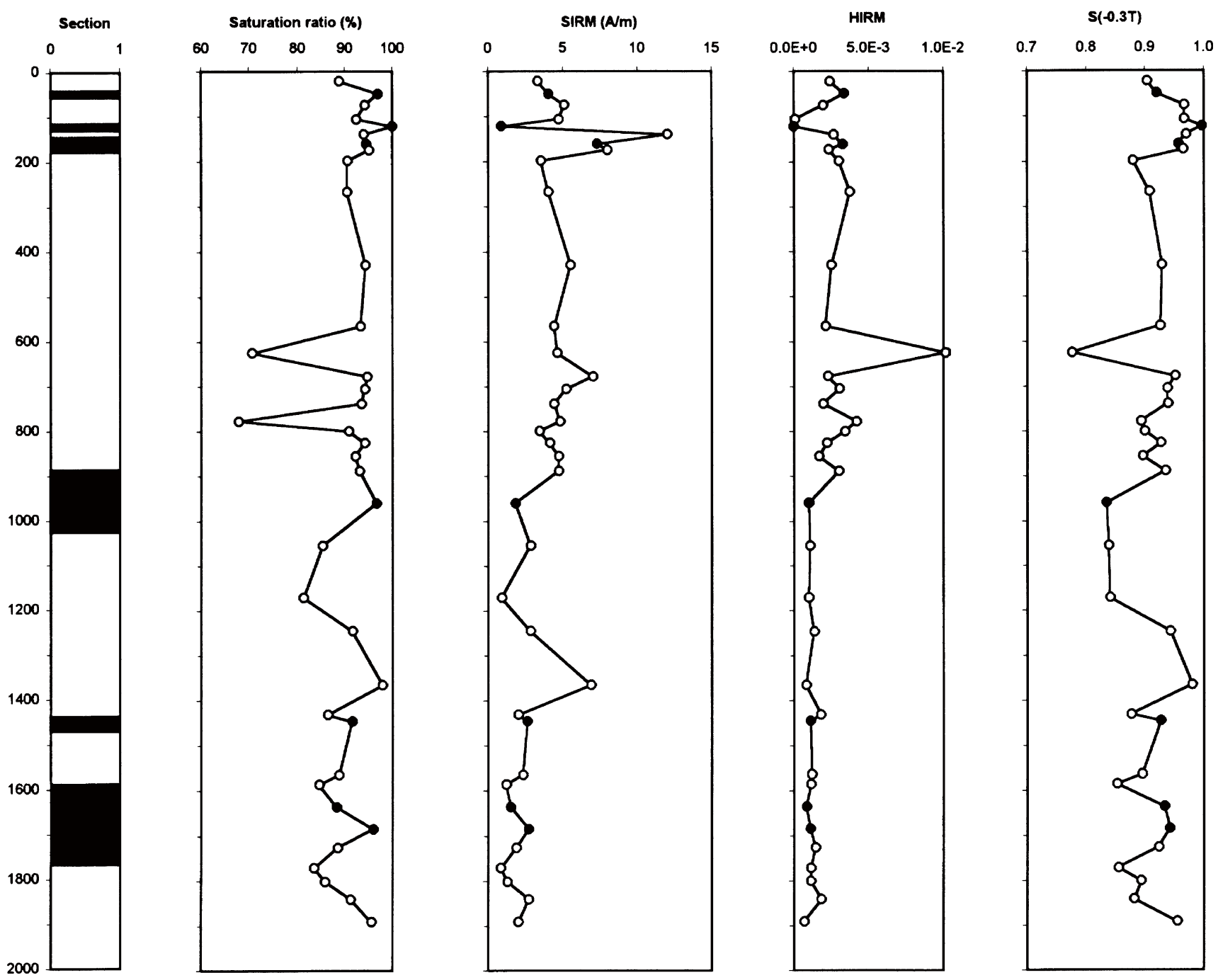

Fig. 5. Variations of the IRM saturation ratio $S_{(1.0 \mathrm{~T}-0.3 \mathrm{~T})}=\left[1-\left\{\left(\mathrm{IRM}_{1.0 \mathrm{~T}}-\mathrm{IRM}_{0.3 \mathrm{~T}}\right) / \mathrm{IRM}_{1.0 \mathrm{~T}}\right\}\right] \times 100(\%), \operatorname{SIRM}(\mathrm{IRM}$ at $2.6 \mathrm{~T})$, HIRM $=$ $\left(\operatorname{IRM}_{-0.3 \mathrm{~T}}+\mathrm{SIRM}\right) / 2$, and the mineral-magnetic parameter $S_{-0.3 \mathrm{~T}}=\left\{\left(-\mathrm{IRM}_{-0.3 \mathrm{~T}} / \mathrm{SIRM}\right)+1\right\} / 2$, in the Haro River Loess-Paleosol sequence. Open circles: loess data, closed circles: paleosol data.

level of the SIRM variation in the overall sequence, except for the PS-3 paleosol, which means that the concentration of total ferrimagnetic (ferromagnetic) materials in the paleosols is not enhanced within this sequence (Fig. 5).

SIRM and back-field IRM values yield useful parameters for estimating the enrichment of low coercivity or high coercivity minerals in the samples. The "hard IRM" (HIRM), (Robinson, 1986; King and Channell, 1991), in Yoshida et al. (1994) is a parameter defined as follows:

$$
\mathrm{HIRM}=\left(\mathrm{IRM}_{-0.3 \mathrm{~T}}+\mathrm{SIRM}\right) / 2
$$

where the IRM-0.3T denotes $0.3 \mathrm{~T}$ back-field IRM values. The HIRM is a measure of the concentration of high coercivity minerals, where HIRM values become large if high coercivity minerals are relatively abundant. Another parameter, $S_{-0.3 \mathrm{~T}}$ is a contrasting measure to indicate the relative abundance of low coercivity mineral (Bloemendal et al., 1992):

$$
S_{-0.3 \mathrm{~T}}=\left[\left(-\mathrm{IRM}_{-0.3 \mathrm{~T}} / \mathrm{SIRM}\right)+1\right] / 2 .
$$

Therefore the value of HIRM suggests that the proportion of high coercive minerals is low within the total ferromagnetic population. And the parameter $S_{-0.3 \mathrm{~T}}$ indicates that the population of low coercive mineral is high within the total ferromagnetic population in this sequence, i.e. magnetite/ maghemite are major magnetic carriers in this sequence. Stratigraphic variations of these two parameters, $S_{-0.3 \mathrm{~T}}$ and HIRM, are displayed in Fig. 5.

\subsection{ARM}

ARM was acquired by exposing bulk samples under a peak alternating field of $100 \mathrm{mT}$ with $(50 \mathrm{~Hz})$ with a constant field of $0.05 \mathrm{mT}$ generated by a modified alternating-field demagnetizer Natsuhara DEM-8601C. The intensity of acquired ARM ranges from $1 \times 10^{-2} \sim 6 \times 10^{-2} \mathrm{~A} / \mathrm{m}$ (Fig. 6). The ARM intensity of some paleosols (PS-1, PS-3, and PS6 ) shows higher values than surrounding loess deposits, and rather low at other paleosol horizons (PS-2, PS-4, PS-5, and PS-7).

The intensity values of SIRM and ARM are basically concentration-dependent parameters. They depend on the grain-size and amount of magnetic materials present. To remove the effect of concentration and obtain only the 

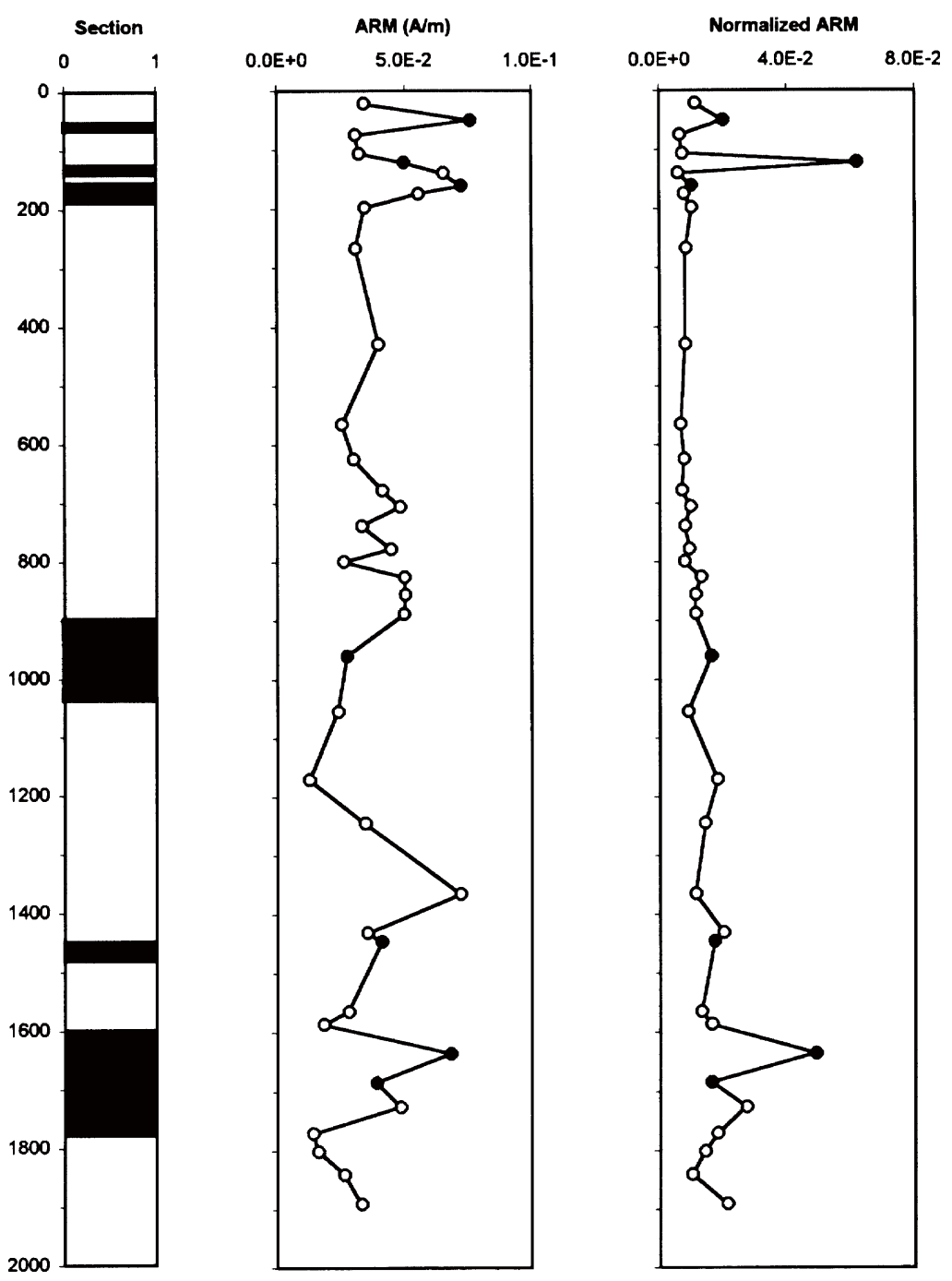

Fig. 6. Variations of ARM and normalized ARM = (ARM/SIRM $)$ in the Haro River Loess-Paleosol sequence. Open circles: loess data, closed circles: paleosol data.

intrinsic changes in the grain-size (=domain state) and/or mineralogy of the magnetic carrier, the ARM intensity is normalized by SIRM which gives the maximum remanance achievable. It has been considered that ARM is particularly sensitive to ultra-fine grains in the single domain (SD) and pseudo single domain (PSD) state (Banerjee et al., 1981; Jackson et al., 1988), hence the relative variation in the content of SD and PSD grains can be approximated by the normalized ARM values to the corresponding SIRM values (Hus and Han, 1992; Hunt et al., 1995):

\section{Normalized ARM = ARM/SIRM.}

The stratigraphic variation curve of the normalized ARM values is comparatively high at the paleosols specially at PS2 and PS-6, as compared to loess (Fig. 6). The curve of normalized ARM reveals that there is some enrichment of ultra-fine ferrimagnetic minerals (magnetite and maghemite) grains within the paleosol horizons.

\section{Magnetic Susceptibility}

The low-field magnetic susceptibility depends on the concentration of magnetic (especially ferromagnetic) min- erals, and their grain-size. The low-field volume magnetic susceptibility of the loess-paleosol deposits was measured by susceptibility meters in the field (Geofyzika KT-5 kappameter, measuring frequency $=10 \mathrm{kHz}$ ) as well as in the laboratory (Bartington MS-2, dual measuring frequencies = $4.7 \mathrm{kHz}$ and $0.47 \mathrm{kHz}$ ). The susceptibility readings depend on the frequency of the applied field (Bhathal and Stacey, 1969). The frequency dependence factor $F$ was computed from the dual-frequency measurement data measured with the MS-2 susceptibility meter as follows (Dearing, 1994). The actual value of $F$ provides qualitative data of grain-size information:

$$
F=\left\{\left(k_{\mathrm{lf}}-k_{\mathrm{hf}}\right) / k_{\mathrm{lf}}\right\} \times 100 \%
$$

where $k_{\text {lf }}$ and $k_{\text {hf }}$ were measured in low $(0.47 \mathrm{kHz})$ and high $(4.7 \mathrm{kHz})$ frequency fields, respectively.

The stratigraphic variation of magnetic susceptibility values (SI unit) in the Loess-Paleosol sequence is shown in Fig. 7. The magnetic susceptibility values measured in the laboratory (MS-2) and the one measured in the field (KT-5) are highly comparable.

Magnetic susceptibility values in and around the upper 

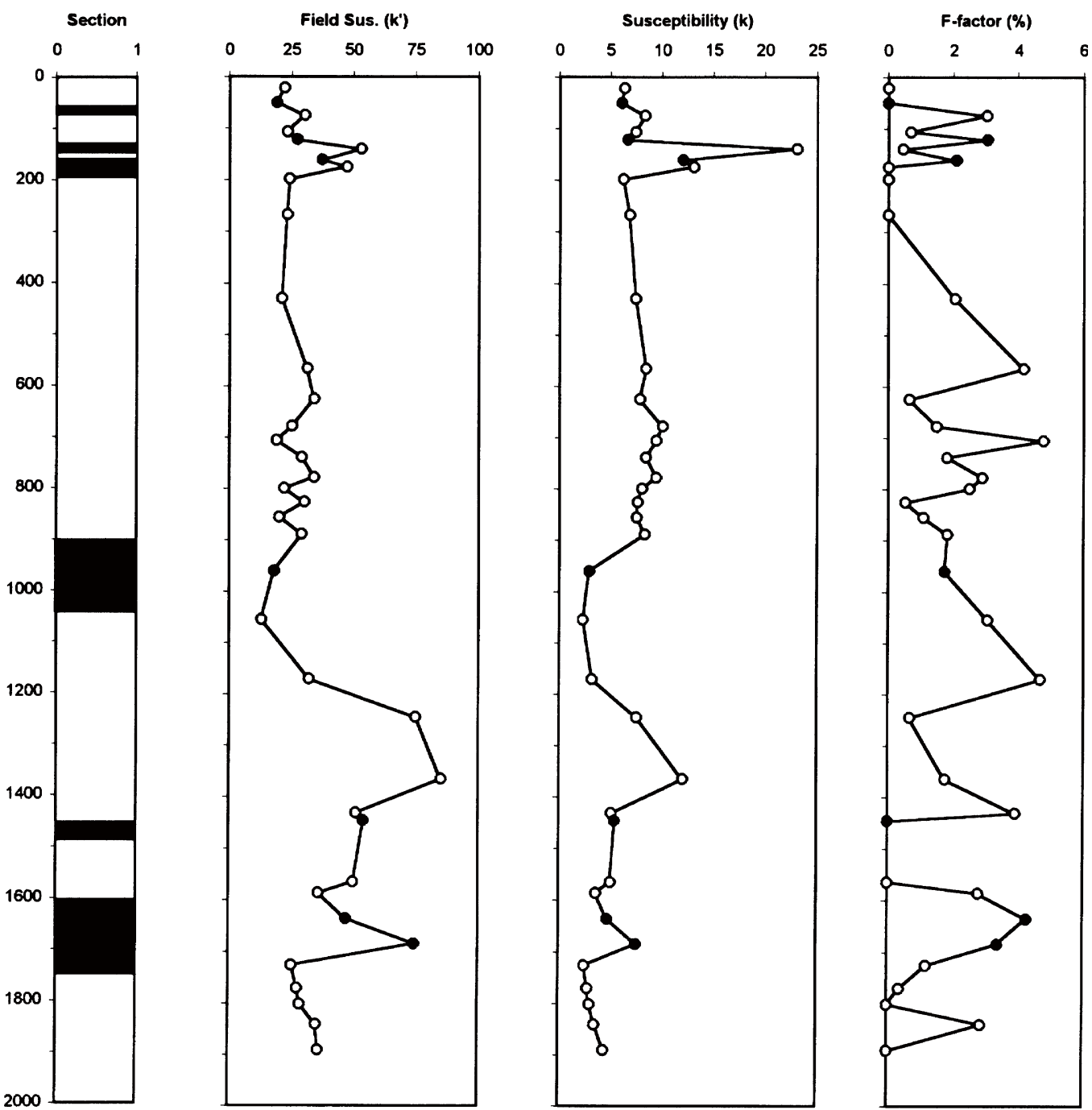

Fig. 7. Variation of low-field volume magnetic susceptibility values (field and laboratory measurements) in the Haro River Loess-Paleosol sequence. $F$-factor is the frequency dependence factor given by $F=\left\{\left(k_{\mathrm{lf}}-k_{\mathrm{hf}}\right) / k_{\mathrm{lf}}\right\} \times 100(\%)$. Open circles: loess data, closed circles: paleosol data.

paleosols zone (PS-1, 2, and 3) and lower paleosol zone (PS$5,6$, and 7$)$ are relatively high $\left(4.7\right.$ to $\left.12.05 \times 10^{-5}\right)$ while that of the PS-4 (middle paleosol) is rather low $\left(2.7 \times 10^{-5}\right)$. It can be recognized that remarkably high susceptibility values often appear immediately below the paleosol horizons (PS2 and PS-3).

There is a proportional relationship between SIRM and magnetic susceptibility (Fig. 8). The SIRM values show that the concentration of ferromagnetic minerals, upon which the enhancement of magnetic susceptibility depends, is not generally high in the paleosol.

\section{Discussion}

\subsection{Magnetic minerals in the Haro River Loess-Paleosol deposits}

The results of thermomagnetic analysis reveals the presence of magnetite, maghemite and goethite as ferromagnetic (ferrimagnetic) minerals. Hematite was not detected in these analyses. The IRM and back-IRM acquisition experiments acquired under the $2.5 \mathrm{~T}$ revealed the presence of magnetite/ maghemite along with some high coercive mineral, maybe goethite (Fig. 4).

In case of paleosols the values of parameter $S_{(-0.3 T)}$ are lying on the higher side (0.9 to 1.0) of the graph, except for PS-4, suggesting the relative abundance of low coercive magnetite/maghemite and the values of HIRM are lying on the lower side of the graph showing low proportion of high coercive minerals like goethite, in the paleosols as compared to loess (Fig. 5). The SIRM discloses that the amount of ferromagnetic minerals is low throughout the sequence, rather low in paleosols as compared to loess in this sequence. Saturation ratio also shows that magnetite/ maghemite are present in abundance in this specially at the paleosols. So all the above analysis suggests that the major magnetic carrier in these deposits is magnetite/maghemite. Furthermore it may be suggested that this relative abundance of magnetite/maghemite is possibly related to the soil forming (pedogenic) process.

We are well aware of the fact that ARM is strongly dependent on grain-size. In SD it shows a large value and decreases to low values at the transition between PSD and MD. The relative variations in the content of SD and PSD grains can be approximated by normalizing the ARM values with the corresponding SIRM values to obtain Normalized ARM (Hunt et al., 1995). In our case the ARM values reveal that SD and PSD grains are relatively enriched in this 


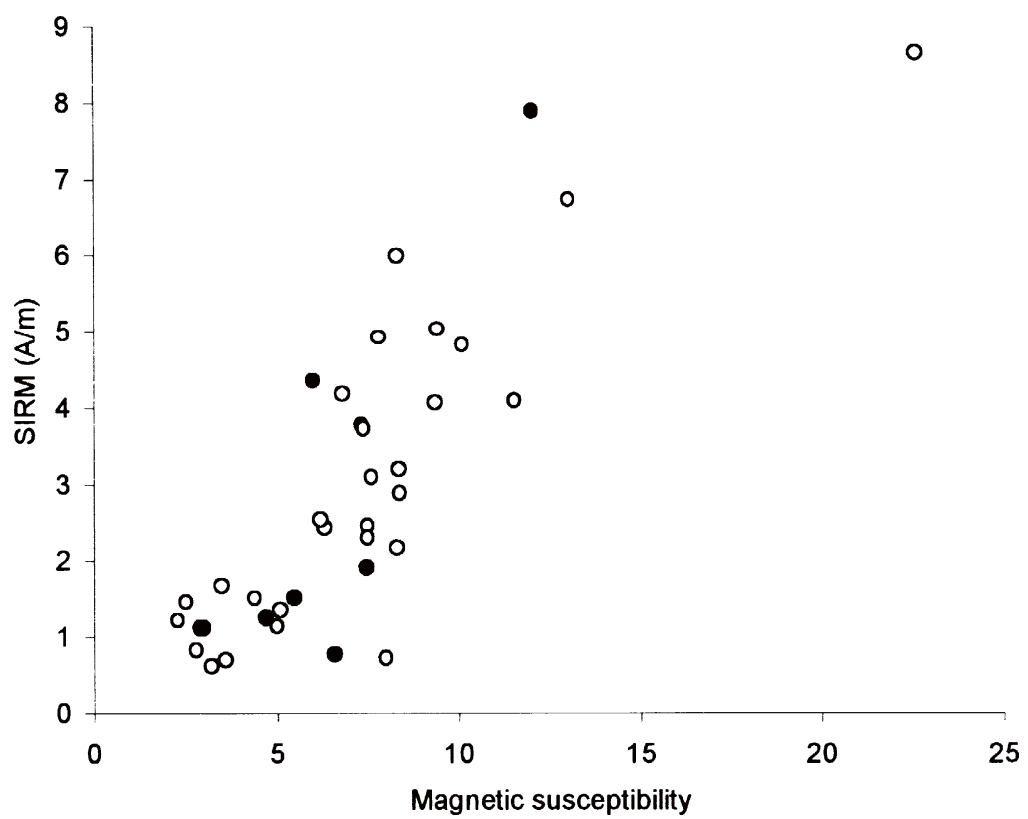

Fig. 8. A proportional relationship can be established between magnetic susceptibility $(k)$ and SIRM (A/m) of Haro River Loess-Paleosol deposits. Open circles: loess data, closed circles: paleosol data.

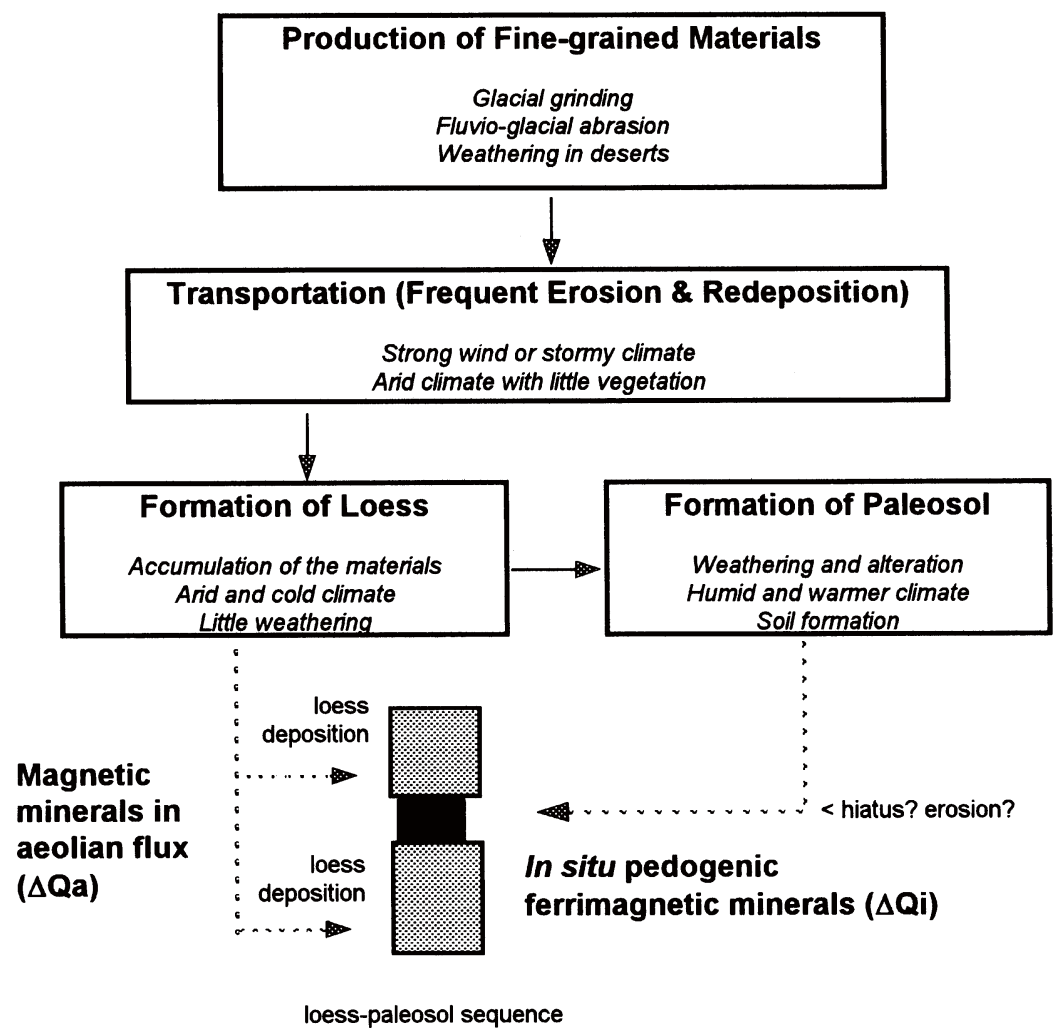

Fig. 9. Formation process suggested for the Pakistani Loess-Paleosol sequence. If the fluctuation in the quantity of magnetic minerals in aeolian flux origin is larger than the quantity of in situ pedogenic ferrimagnetic minerals $\left(\Delta Q_{\mathrm{a}}>\Delta Q_{\mathrm{i}}\right)$, the magnetic susceptibility variation may not correlate with Loess-Paleosol alternation.

sequence (Fig. 6). While the normalized ARM shows that there is some enhancement in the paleosol layers, specially PS-2 and PS-6, meaning that there is some enrichment of ultra-fine grains in the paleosols. It may suggest that the in situ formation of ultra-fine (SD and PSD) magnetite/ maghemite grains (Maher and Taylor, 1988; Evans and
Heller, 1994) occurred during the soil forming (Pedogenic) process.

\subsection{Variation in magnetic susceptibility}

The magnetic susceptibility of the Haro River LoessPaleosol deposits is mainly contributed by the presence of ferromagnetic (ferrimagnetic) minerals such as magnetite, 
maghemite, and goethite. Apart from these ferromagnetic minerals, biotite, hornblende, and other clay minerals occur as paramagnetic minerals whereas quartz and plagioclase occur as diamagnetic minerals.

The magnetic susceptibility enhancement in the paleosol layers depends upon concentration, grain-size, and mineralogy of the ferromagnetic mineral present. High magnetic susceptibility values of Haro River Loess-Paleosol sequences do not simply correlate with the paleosol layers, and therefore it is incompatible with the well-known magnetic susceptibility variation in the loess-paleosol sequences of the Chinese Loess Plateau. The intensity of SIRM values also confirms that the concentration of ferromagnetic minerals is not high in the paleosols (Fig. 8). Magnetic susceptibility of Haro River Loess-Paleosol sequence shows no systematic difference between loess and paleosol as expected from numerous earlier investigations on Chinese Loess Plateau.

\subsection{Paleoenvironment}

It has generally been believed that in situ formation of ferrimagnetic minerals during pedogenesis plays a vital role in the enhancement of magnetic susceptibility. Apart from this, input of magnetite grains by local wind could also accidentally enhance the magnetic susceptibility (Fig. 9). So together the two processes play an important role in the enhancement of magnetic susceptibility (Evans and Heller, 1994). In the Haro River Loess-Paleosol sequence the in situ formation of magnetite, which normally enhances the magnetic susceptibility, is weak. On the other hand fluctuation of the input of magnetic grains by local winds is probably more significant than the in situ enhancement (Fig. 9).

It is the in situ pedogenesis which basically plays a very important role in the magnetic susceptibility enhancement of loess-paleosol sequences in China. The enhancement of in situ pedogenic ultra-fine magnetite/maghemite in paleosols is thought to depend on paleo-precipitation (rainfall) values (Maher and Thompson, 1992; Heller et al., 1993; Maher, 1996). In our case the presence of pedogenic ultra-fine magnetite/maghemite at paleosol units is not doubtful, but its amount is probably insufficient to enhance the magnetic susceptibility of paleosol units. It may be suggested that the climate was not very humid and warm and the paleosols could not develop properly because of the unfavorable climate, or this may result from low rainfall in the area during the pedogenesis in late Pleistocene. The occurrence of halite (an indicator of a very arid conditions) in the sequence, even from the paleosols, supports this assumption. Thus this situation is quite different from the Chinese LoessPaleosol sequence.

This type of "non Chinese Loess Plateau type" magnetic susceptibility variation, has already been reported from some places in Europe and North America (Heller and Evans, 1995). The results from Poland (Maruszezak and Nawrocki in Heller and Evans, 1995) and Alaska (Beget et al., 1990) give relatively lower magnetic susceptibility values for paleosols, which is a reversed relationship of susceptibility enhancement as compared to China. In the case of the Alaskan Loess-Paleosol sequence, it was argued that local winds were stronger during glacial intervals and therefore more magnetite (influx) was supplied, so the magnetic susceptibility values were high in case of the loess as compared to the paleosols (Beget et al., 1990).

A similar situation might be the case with the Haro River deposits, where magnetic susceptibility is not fully influenced by the in situ formation of ferrimagnetic minerals formed during the pedogenic process. The paleosols in the section were probably formed under a different environment accommodating relatively weaker pedogenic activity resulting from low rainfall. In this condition, other factors enhancing magnetic susceptibility such as fluctuations of the influx of magnetic grains by local winds could contribute to the variation of magnetic susceptibility (Fig. 9). The presence of sand-size grains supplied by strong local winds is reported by Nizam-Din and Yoshida (1997) on the basis of particle-size distribution analyses. This also supports the present argument.

Despite the fact that the ultra-fine grained magnetite/ maghemite grains were formed due to pedogenesis in paleosols, the low-field magnetic susceptibility record does not directly correlate with the alteration of the Haro River Loess-Paleosol sequence, and therefore can not simply act as a proxy for paleoclimate. Thus, one should not automatically translate magnetic susceptibility changes in loesspaleosol sequences into a proxy measure of paleoclimatic change.

\section{Conclusions}

(1) The major ferromagnetic (ferrimagnetic) minerals in the Haro River Loess-Paleosol sequence are magnetite and maghemite. The variation of low-field magnetic susceptibility in the loess-paleosol sequence is mostly attributed by changes in the amount of these minerals.

(2) Ultra-fine magnetite/maghemite grains are generally enhanced at paleosol units, which suggests that some of the magnetite/maghemite in the paleosol units are of pedogenic origin. However the change of bulk magnetic susceptibility value cannot be correlated with loess-paleosol sequence, (as it has been done in Chinese Loess-Paleosol) and this may be weak pedogenesis activity under an arid condition.

(3) The loess-paleosol sequence in Attock basin, Pakistan does not show "Chinese Loess Plateau type" correlation between magnetic susceptibility and loess/paleosol facies. It suggests that magnetic susceptibility variation in loesspaleosol sequences does not always give a simple proxy measure for paleoclimatic change.

Acknowledgments. We wish to thank Nizam-Din for his generous assistance in the field and in the laboratory. We also thank Tahir Karim, Iftikhar Mustafa Khadim, Haider Zaman, Rehanul Haq Siddiqui, and Muhammad Zafar for their valuable suggestions. This paper is an outcome of international technical cooperation project, the Geoscience Laboratory Project, between the Geological Survey of Pakistan (GSP) and the Japan International Cooperation Agency (JICA).

\section{References}

Banerjee, S. K., J. W. King, and J. Marvin, A rapid method for magnetic granulometry with application to environmental studies, Geophys. Res. Lett., 8, 333-336, 1981.

Beget, J. E., D. B. Stone, and D. B. Hawkins, Paleoclimatic forcing of magnetic susceptibility variations in Alaskan loess during the late Quaternary, Geology, 18, 40-43, 1990. 
Bhathal, R. S. and F. D. Stacey, Frequency dependence of low-field susceptibility of rocks, J. Geophys. Res., 74, 2025-2027, 1969.

Bloemendal, J., J. W. King, F. R. Hall, and S. J. Doh, Rock magnetism of late Neogene and Pleistocene deep-sea sediments: Relationship to sediment source, diagenetic processes, and sediment lithology, $J$. Geophys. Res., 97, 4361-4375, 1992.

Chlachula et al., Environmental magnetism, CJESS, 34, 679-686, 1997.

Dearing, J., Environmental Magnetic Susceptibility, Using the Bartington MS2 System, 104 pp., Bartington Instruments, Oxford, 1994.

Evans, M. E. and F. Heller, Magnetic enhancement and paleoclimate. Study of a loess/paleosol couplet across the Loess Plateau of China, Geophys. J. Int., 117, 257-264, 1994.

Forster, T. and F. Heller, Loess deposits from the Tajik depression (Central Asia): Magnetic properties and paleoclimate, Earth Planet. Sci. Lett., 128, 501-512, 1994.

Heller, F. and M. E. Evans, Loess magnetism, Rev. Geophys., 33, 211 240, 1995.

Heller, F. and T. Liu, Magnetostratigraphical dating of loess deposits in China, Nature, 300, 43, 1982.

Heller, F. and T. Liu, Magnetism of Chinese loess deposits, Geophys. J. R. Astron. Soc., 77, 125-141, 1984.

Heller, F., X. Liu, T. Liu, and T. Xu, Magnetic susceptibility of loess in China, Earth Planet. Sci. Lett., 103, 301-310, 1991.

Heller, F., C. D. Shen, J. Beer, X. M. Liu, T. S. Liu, A. Bronger, M. Suter, and G. Bonani, Quantitative estimates of pedogenic ferromagnetic mineral formation in Chinese Loess-Paleosol implications, Earth Planet. Sci. Lett., 114, 385-390, 1993.

Hunt, P., S. K. Banerjee, J. Han, P. A. Solheid, W. Sun, and T. Liu, Rockmagnetic proxies of climate change in the Loess-Paleosol sequence of the western loess plateau of China, Geophys. J. Int., 123, 232-244, 1995.

Hus, J. J. and J. Han, The contribution in loess magnetism in China to the retrieval of past global changes-some problems, Earth Planet. Inter. 70, 154-168, 1992.

Jackson, M., W. Gruber, J. Marvin, and S. K. Banerjee, Partial anhysteretic remanance and its anisotropy: Applications and grain-size-dependence, Geophys. Res. Lett., 15, 440-443, 1988.

King, J. W. and J. E. T. Channell, Sedimentary magnetism, environmental magnetism, and magnetostratigraphy, Rev. Geophys. Supplement, U.S National Report to International Union of Geodesy and Geophysics 1987-1990: Contribution in Geomagnetism and Paleomagnetism, 358$370,1991$.

Kukla, G., F. Heller, X. Liu, T. Xu, T. Liu, and Z. An, Pleistocene climates in China dated by magnetic susceptibility, Geology, 16, 811-814, 1988

Liu, T. S. et al., Loess and the Environment, 251 pp., China Ocean Press, Beijing, 1985.

Liu, X., J. Shaw, T. Liu, F. Heller, and M. Cheng, Rock magnetic properties and palaeoclimate of Chinese loess, J. Geomag. Geoelectr., 45, 117-124, 1993.

Liu, X., T. Rolph, J. Bloemendal, J. Shaw, and T. Liu, Remanance characteristics of different magnetic grain size categories at Xifeng, central Chinese Loess Plateau, Quaternary Res., 42, 162-165, 1994.

Maher, B. A., Glacial/interglacial variations in monsoon intensity from magnetic proxies in the Chinese Loess Plateau, Eos Trans. AGU, Suppl., 77(22), W23, 1996.

Maher, B. A. and R. M. Taylor, Formation of ultra-fine-grained magnetite in soils, Nature, 336, 368-370, 1988.

Maher, B. A. and R. Thompson, Paleoclimatic significance of the mineral magnetic record of the Chinese loess and paleosols, Quaternary Res., 37, 155-170, 1992.

Nizam-Din and M. Yoshida, Particle-size distribution of late Pleistocene Loess-Paleosol deposits in Attock basin, Pakistan: Its paleoclimatic implications, Quaternary Res., 37, 1-11, 1997.

Oches, E. A. and S. K. Banerjee, Glacial-interglacial records from northern hemisphere loess: a comparison of magnetic and non-magnetic proxies for late Pleistocene climate change, Eos Trans. AGU, Suppl., 77(22), W23, 1996.

Rendell, H., Environmental changes during the Pleistocene in the Potwar Plateau and Peshawar Basin, Northern Pakistan, in Paleoclimatic and Paleoenvironmental Changes in Asia during the Last 4 Million Years, edited by D. V. S. Jain, Indian National Science Academy, 291, 58-66, 1988 .

Rendell, H., Loess deposition during the Late Pleistocene in Northern Pakistan, Z. Geomorph. N. E., 76, 247-255, 1989.

Robinson, S. G., The late Pleistocene paleoclimatic record of North Atlantic deep-sea sediments revealed by mineral-magnetic measurements, Phys. Earth Planet. Inter., 42, 22-47, 1986.

Siddiqui, R. H., Mineralogy of late Quaternary Haro River Loess-Paleosol deposits, Attock district, Punjab, Pakistan, Proc. Geosci. Colloq., Geosci. Lab., Geol. Surv. Pakistan, 14, 107-116, 1996.

Verosub, K. L., P. Fine, M. J. Singer, and J. TenPas, Pedogenesis and paleoclimate: Interpretation of the magnetic susceptibility record of Chinese Loess-Paleosol sequences, Geology, 21, 1011-1014, 1993.

Yoshida, M., I. M. Khadim, M. Ali, and M. N. Ahmad, Magnetic Approaches to Geological Sciences, Geoscience Lecture Series, No. 3, 85-95, 1994.

Zafar, M., H. Akram, and M. Yoshida, Major elements composition of Haro River Loess-Paleosol deposits, Attock district, Pakistan, Proc. Geosci. Colloq., Geosci. Lab., Geol. Surv. Pakistan, 14, 117-124, 1996.

Zheng, H., F. Oldfield, L. Yu, J. Shaw, and Z. An, The magnetic properties of particlesized samples from the Luo Chuan loess section: evidence for pedogenesis, Phys. Earth Planet. Inter., 68, 250-258, 1991.

Zheng, H., T. Rolph, J. Shaw, and Z. An, A detailed paleomagnetic record for the last interglacial period, Earth Planet. Sci. Lett., 133, 339-351, 1995 .

Huma Akram (e-mail: geolab@isb.compol.com), Mitsuo Yoshida, and Mirza Naseer Ahmad 